\title{
EXPLAIN THE CULTURAL NEEDS OF EMPLOYEES, ISLAMIC AZAD UNIVERSITY
}

\author{
Ali Siadat PhD *Hasan Ali Bakhtiar Nasrabadi PhD** Mohadeseh Rabbani*** \\ *Associate Professor and member of Isfahan University, Isfahan, Iran \\ **Associate Professor and member of Isfahan University, Isfahan, Iran \\ *** Khorasgan (Isfahan) Branch, Islamic Azad University, Isfahan, Iran
}

\begin{abstract}
This study aims to develop cultural needs of the Islamic Azad University staff with descriptive - survey was conducted. The population of the entire staff of Islamic Azad University study of 550 formed in the year 90-91. Proportional to size sampling method, the sample was selected. Cochran's sample size formula for sample size of 226 patients was obtained. Means of a questionnaire survey in two parts, the first part of the second part of demographic characteristics and cultural needs of employees was formed. Validity and reliability based on Cronbach's alpha coefficient of experienced professors and 84/0 estimate was confirmed. Both descriptive and inferential data analysis of variance test was performed. The results showed that the average in each of the dimensions necessary to religious ideas, the entertainment - leisure, social, media, sports and culture - art was above average. Results also showed no significant differences in demographic variables at the cultural needs of students.
\end{abstract}

Key words: culture, needs, needs assessment, cultural needs

\section{Introduction}

The characteristic feature of human society and culture that distinguish one community from the other communities. The culture of life and all things created by humans will take. Cultural needs of diverse groups and includes important human needs. Required distance between the current situation and the ideal situation there. Needs an important role in the formulation of objectives and organizational planning, particularly on college campuses is because no notice of deficiencies, the possibility of tuning the program, or program is futile to plan. No doubt, nor could any organization nor all individual and community needs with an extensive subset of it does tall. So it is necessary to identify needs. Identify and prioritize needs and preferred means an absolute requirement need not But to identify the needs of the common assessment of needs and the needs of the target application.

\section{1 - Expression issue}

The role and importance of culture in human societies shows that humans have always been cultural needs because the needs of life and is not enough for him [1]. Core concept of need, lack of feeling (and the optimum gap condition) that is Often individual aspects need to be considered, however, is emerged on the need for social and cultural patterns is. The overall concept of the social needs of the organization and has been discussed by experts. Various definitions from different viewpoints is required. From a practical point of view they can be divided into four [2]. Identify the needs of the most important cultural and spiritual needs, as in a community has a significant share in the growth and development of social and cultural institutions that are interpreted to be because Malinowski is the functional response needs of the culture of every society that funded institution-building [3] Institutions such as the family, schools, universities and the media in any way the social and cultural needs of people trying. But it requires the measurement and understanding of the needs of different categories of 
social and cultural needs of the individual. The assessment is a process in which goals, assess the situation, then the priority targets for action is clear.

Organizations in the health and material needs and motivation are very important, while little attention to the spiritual needs of people is not. Though many divide needs to be addressed, but what is less is less concrete and tangible needs the special needs and cultural needs a decisive role in determining the character of an individual and society and hence future generations

It is of particular importance to cultural needs. Cultural needs of specific categories and the categories are distinct, and the level of family, education, peers and etc. Are classified according to different criteria. It needs to be based on gender, age, personal interests, beliefs, and etc. Are different. Cultural life of the community is manifested in two aspects: activities and participation in cultural production and cultural creativity. Cultural activities including key concepts related to cultural life.

To the cultural needs, expectations that people have the leisure and the means of cultural goods and services are completed at your leisure. These activities can be classified into the following activities:

\section{A) Religious activity:}

Human orientation to the sacred religious and paranormal activity leads her to. An important part of religious activities should be manifested in behavior. Religious practices and religious communities (both natal and mourning), participating in a religious lecture halls, attending prayers and Quran in prayer and Friday, from visiting graves, reading the Koran and attend Secretions, including activities are religious.

B) Social activities:

Orientation and sense of altruism and other necessities of life, human beings tend to make social activities. Participation in social activities through membership in community activities such as scientific associations, cultural associations, Islamic organizations, charitable and community mobilization is possible.

C) exercise:

Do physical exercises to strengthen and regenerate the individual and the exercise of power loss. Watch and follow sports news and information on sporting events, is also among the sports activities.

D) Activities Art: The artistic activities, actions and activities that imagination and visualization, it is the original yeast. The product of this type of activity is a growing hobby.

Including media activities is considered [4].

The difference between needs, values, norms and characteristics of any society, the community comes in the form of culture. Need to develop a new program, and a review of current programs is therefore essential that an incentive to fulfill the cultural assessment of employee pay. Planners hope to study Cultural Affairs, is useful.

\section{2- Research questions}

1 - the most important Islamic Azad University staff What are the cultural needs?

2 - The most important Islamic Azad University staff in the religious and cultural needs what?

3 - The most important cultural needs of employees, Islamic Azad University, leisure resorts in the what?

4 - The most important cultural needs of the sports staff of Islamic Azad University, What? 
5 - Islamic Azad University staff is the most important cultural needs of the cultural dimension - what is art?

6 - Islamic Azad University staff are the most important cultural needs of the cultural dimension - what media?

7 - Islamic Azad University staff are the most important cultural needs of the community then what?

8 - Islamic Azad University of the cultural needs of employees with different demographic characteristics?

\section{3- Materials and Methods}

Method in research is descriptive. Survey of all Islamic Azad University staff, including contractors, and official count is 550 people who have worked 90-91 years. Sample size of 237 patients was assessed using Cochran's sampling formula. In this study, a stratified random sample proportional the volume. Cronbach's alpha reliability of the questionnaire through an $84 / 0$, respectively.

\section{4- Research findings}

In this section, analytical research findings based on research questions that have been set.

First question: Cultural needs staff of Islamic Azad University in the area of religious culture, what are the elements?

Table1- the value of $t$, the significance level and the average rate associated questions religious needs

\begin{tabular}{llllll}
\hline & & & & $\mathbf{1}$ \\
\hline $\begin{array}{l}\text { Exhibitions related to each chapter of the Qur'an and } \\
\text { Household. }\end{array}$ & $23 / 922$ & $10 / 39$ & $0 / 001$ & 217 \\
\hline Koran teach one day per week & $22 / 269$ & $9 / 54$ & $0 / 001$ & 225 \\
\hline Quran meeting one day per week & $23 / 356$ & $9 / 60$ & $0 / 001$ & 225 & \\
\hline $\begin{array}{l}\text { Special Qur'an tournament staff } \\
\text { As family celebrations and religious festivals }\end{array}$ & $27 / 797$ & $10 / 35$ & $0 / 001$ & 225 & $\mathbf{2}$ \\
\hline Holding mourning rituals in family and & $10 / 761$ & $10 / 10$ & $0 / 001$ & 225 & $\mathbf{5}$ \\
\hline Holding religious prayers in the family & $14 / 287$ & $8 / 55$ & $0 / 001$ & 225 & \\
\hline $\begin{array}{l}\text { Quran teaching staff of special family } \\
\text { Respond to religious questions via short message } \\
\text { system }\end{array}$ & $16 / 877$ & $9 / 46$ & $0 / 001$ & 225 & \\
\hline $\begin{array}{l}\text { Board of mourning and celebration among employees } \\
\text { Strengthen cultural activities mobilize staff }\end{array}$ & $16 / 510$ & $9 / 12$ & $0 / 001$ & 225 & \\
\hline $\begin{array}{l}\text { Holding time, congregational prayers in the mosque } \\
\text { regularly spiteful }\end{array}$ & $27 / 128$ & $9 / 69$ & $0 / 001$ & 225 \\
\hline $\begin{array}{l}\text { Send convoys of martyrs Vance light path to visit war } \\
\text { zones }\end{array}$ & $26 / 388$ & $10 / 81$ & $0 / 001$ & 225 & $\mathbf{3}$ \\
\hline
\end{tabular}




\begin{tabular}{llllll}
\hline Camp visit holy shrines of Imam Khomeini & $17 / 981$ & $10 / 91$ & $0 / 001$ & 225 & $\mathbf{4}$ \\
\hline Cultural programs and activities known definitely deny & $13 / 448$ & $8 / 57$ & $0 / 001$ & 225 & \\
\hline Pilgrimage held on the last Thursday of each month & $26 / 066$ & $8 / 72$ & $0 / 001$ & 225 \\
\hline Held in the Memorial University of unknown martyrs & $23 / 218$ & $9 / 71$ & $0 / 001$ & 225 \\
\hline Quran recitation and prayer play in office space & $20 / 999$ & $9 / 03$ & $0 / 001$ & 225 \\
\hline
\end{tabular}

According to Table 1- $\mathrm{t}$ calculated for all questions is bigger than $\mathrm{t}$ table. So either the religious needs of the ocean is more than average. Each of these questions is "camp visit holy shrines of Imam Khomeini", "light path convoys sent to war zones Vance visited the Martyrs", " exhibitions related to each chapter of the Qur'an," "Quran competitions, especially the staff" "family celebrations and religious festivals as" the highest average rank is assigned to.

\section{Second question: the cultural needs of employees, Islamic Azad University, leisure resorts in the area, include what elements?}

Table 2- The value of $t$, and the average rate associated with significant needs and leisure Essay contest for various special occasions

\begin{tabular}{llllll}
\hline & & & & & \\
& & & & \\
\hline Tournament in Reading & $20 / 306$ & $3 / 87$ & $0 / 001$ & 225 & $\mathbf{3}$ \\
\hline Creating and establishing small libraries in each & $30 / 205$ & $4 / 53$ & $0 / 001$ & 225 & \\
\hline Weekly Tournament in the form of various topics & $21 / 471$ & $4 / 24$ & $0 / 001$ & 225 & \\
\hline Entrepreneurship courses & $20 / 879$ & $3 / 85$ & $0 / 001$ & 225 & $\mathbf{2}$ \\
\hline Children's sports teams composed of staff & $28 / 621$ & $4 / 15$ & $0 / 001$ & 225 & $\mathbf{1}$ \\
\hline Family safari camps held each month & $19 / 104$ & $3 / 47$ & $0 / 001$ & 225 & \\
\hline
\end{tabular}

According to Table 2- $t$ calculated for all questions is bigger than $t$ table. So either the leisure needs of the ocean is more than average. Also, each of the questions, "tournament Reading", "creating and establishing small libraries in each episode," "entrepreneurship courses," "family safari camps held each month," "essay contest for various special occasions "The arrangement is allocated to the highest average ratings. 
Third question: the cultural needs of the Islamic Azad University staff in the area of sports, including what elements?

Table3-The value of t and the average rate associated with significant sporting needs

\begin{tabular}{lccccc}
\hline & & & & & \\
& & $32 / 297$ & $3 / 58$ & $0 / 001$ & 225 \\
\hline Family sports events (hiking, mountain tour ...) & $39 / 609$ & $4 / 39$ & $0 / 001$ & 225 & $\mathbf{2}$ \\
\hline $\begin{array}{l}\text { Various sports competitions } \\
\text { The academic staff of the club teams in various sports } \\
\text { fields }\end{array}$ & $30 / 581$ & $3 / 93$ & $0 / 001$ & 225 & $\mathbf{5}$ \\
\hline Shopping facilities, sporting & $35 / 994$ & 4 & $0 / 001$ & 217 & $\mathbf{3}$ \\
\hline Physical training, such as yoga, meditation and ... & $28 / 560$ & $3 / 97$ & $0 / 001$ & 225 & $\mathbf{4}$ \\
\hline Children's sports teams composed of staff & $17 / 955$ & $3 / 51$ & $0 / 001$ & 216 & \\
\hline Sport Tournament in each season. & $38 / 247$ & $4 / 63$ & $0 / 001$ & 218 & $\mathbf{1}$ \\
\hline
\end{tabular}

According to Table 3- $\mathrm{t}$ calculated for all questions is bigger than $\mathrm{t}$ table. So each of the tales sports needs to be more moderate. Each of these questions is "Sport Tournament in every season", "holding various sports", "sports facilities, purchase equipment", "fitness training such as yoga, meditation, and ...", "inter-collegiate club teams formed employees in various fields of sports' highest average rank is assigned to.

Question Four: Cultural needs staff of Islamic Azad University in the area of culture - art, including what elements?

Table 4- The value of $t$, and the average rate associated with significant cultural needs Henry

\begin{tabular}{|c|c|c|c|c|c|}
\hline & - & 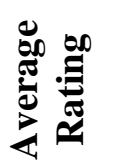 & 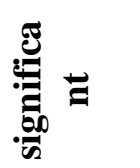 & 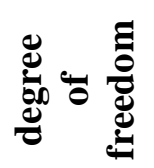 & \\
\hline Art training courses for employees & $31 / 122$ & $3 / 74$ & $0 / 001$ & 225 & 1 \\
\hline $\begin{array}{l}\text { Cultural exhibitions of art works of employees and } \\
\text { their families }\end{array}$ & $20 / 449$ & $3 / 16$ & $0 / 001$ & 225 & \\
\hline Couple Celebrating Success (Arts and Education) staff & $24 / 911$ & $3 / 70$ & $0 / 001$ & 216 & 2 \\
\hline Understanding economic approaches to art & $21 / 924$ & $3 / 47$ & $0 / 001$ & 225 & 3 \\
\hline Traditional and Indigenous Arts Education Zone of Iran & $27 / 605$ & $3 / 70$ & $0 / 001$ & 225 & 4 \\
\hline $\begin{array}{l}\text { Understanding the cultural and educational centers in } \\
\text { Iran - World }\end{array}$ & $32 / 697$ & $3 / 23$ & $0 / 001$ & 225 & 5 \\
\hline
\end{tabular}


According to Table 4- $t$ calculated for all questions is bigger than $t$ table. So each of the tales of cultural needs - Art is more than average. Each of these questions is "Art for staff training," "failed to honor their wives (Arts and Education) staff," "authentic Aboriginal arts education in every region of the country", "Understanding economic approaches to art" "Understanding the cultural and educational centers in Iran - The world of" the highest average rank is assigned to.

Question Five: Cultural needs staff of Islamic Azad University in the area of culture - media, including what elements?

Table 5- The value of $t$, and the average rate associated with significant media needs

\begin{tabular}{|c|c|c|c|c|c|}
\hline & - & 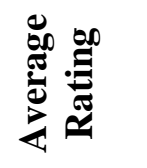 & 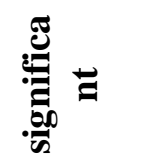 & 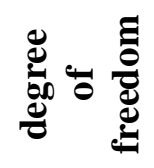 & 气્ \\
\hline $\begin{array}{l}\text { Special Publication cultural issues of the day, for } \\
\text { workers }\end{array}$ & $24 / 757$ & $4 / 17$ & $0 / 001$ & 225 & 4 \\
\hline Creating Cultural panels & $13 / 974$ & $3 / 71$ & $0 / 001$ & 225 & 5 \\
\hline Cultural transmission of information via the website & $32 / 495$ & $4 / 48$ & $0 / 001$ & 225 & 1 \\
\hline \multicolumn{6}{|l|}{ Installed electronic signs in the area of traffic } \\
\hline Cultural Twitter for special occasions & $33 / 080$ & $4 / 39$ & $0 / 001$ & 225 & 2 \\
\hline $\begin{array}{l}\text { Symptoms and cultural symbols (clothing, cars, etc.) } \\
\text { during the celebration and mourning }\end{array}$ & $14 / 032$ & $3 / 31$ & $0 / 001$ & 225 & \\
\hline \multirow{2}{*}{\multicolumn{6}{|c|}{$\begin{array}{l}\text { According to Table 5- } t \text { calculated for all questions is bigger than } t \text { table. So each of the tales } \\
\text { of the media needs to be more moderate. Each of these questions is "cultural transmission of } \\
\text { information via the site," "cultural Twitter for special occasions", "installing electronic signs } \\
\text { at the traffic people", "Special Publication cultural issues of the day, for workers' "Creating } \\
\text { Cultural panels" in order to account for the highest average ratings. }\end{array}$}} \\
\hline & & & & & \\
\hline & - & 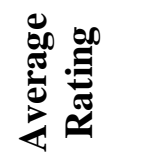 & 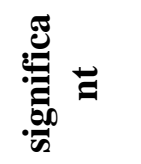 & 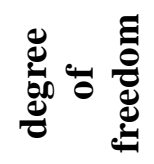 & 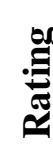 \\
\hline Holding camps, mass (Touring) family in every season & $29 / 403$ & $7 / 77$ & $0 / 001$ & 225 & \\
\hline In celebration of National Family & $43 / 228$ & $8 / 70$ & $0 / 001$ & 217 & 2 \\
\hline $\begin{array}{l}\text { Distribute books on the social and practical life skills } \\
\text { among staff }\end{array}$ & $33 / 084$ & $7 / 86$ & $0 / 001$ & 218 & \\
\hline \multicolumn{6}{|l|}{ A cultural theme for each week. } \\
\hline $\begin{array}{l}\text { Outstanding professors and university lectures in the } \\
\text { field of Events }\end{array}$ & $24 / 474$ & $8 / 61$ & $0 / 001$ & 218 & 3 \\
\hline
\end{tabular}




\begin{tabular}{|c|c|c|c|c|c|}
\hline Introduction Ethics every year in the face of persistent & $22 / 169$ & $8 / 10$ & $0 / 001$ & 225 & \\
\hline Celebration of the privileged children of employees & $24 / 244$ & $7 / 51$ & $0 / 001$ & 216 & \\
\hline Communication skills & $33 / 555$ & $8 / 05$ & $0 / 001$ & 225 & \\
\hline Learning how to balance work and life & $36 / 267$ & $7 / 78$ & $0 / 001$ & 225 & \\
\hline Training Feedback & $25 / 376$ & $7 / 41$ & $0 / 001$ & 225 & \\
\hline Congratulations to staff holidays and special occasions & $34 / 849$ & $8 / 36$ & $0 / 001$ & 225 & 5 \\
\hline $\begin{array}{l}\text { Furnish office space, technical and socio-cultural } \\
\text { rhetoric }\end{array}$ & $21 / 550$ & $7 / 75$ & $0 / 001$ & 216 & \\
\hline $\begin{array}{l}\text { Facilities increased use of cultural products (movies, } \\
\text { books, etc) }\end{array}$ & $37 / 403$ & $8 / 47$ & $0 / 001$ & 225 & 4 \\
\hline $\begin{array}{l}\text { Exhibitions, social and cultural products (books, CDs, } \\
\text { etc.) in each season. }\end{array}$ & $30 / 222$ & $7 / 75$ & $0 / 001$ & 225 & 1 \\
\hline $\begin{array}{l}\text { Participate in off-campus social and cultural } \\
\text { exhibitions }\end{array}$ & $28 / 119$ & $7 / 67$ & $0 / 001$ & 225 & \\
\hline
\end{tabular}

According to Table6- $t$ calculated for all questions is bigger than t table. So either the religious needs of the ocean is more than average. Each of these questions is "furnish office space, technical and socio-cultural rhetoric," "use of eminent professors and university lectures on the occasion," "Social exhibitions of cultural products (books, CDs, etc.) in each season. "" In celebration of National Family, "' increased facilities of cultural products (movies, books, etc.) "," Congratulations to staff holidays and special occasions "arrange their highest average rank is assigned to .

Seventh question: Is the cultural needs of the Islamic Azad University employees with different demographic characteristics?

Table 4-21: ANOVA multivariate scores cultural needs based on gender, age, education, duration of service

\begin{tabular}{lccccc}
\hline & Significant & F & Mean square & $\begin{array}{c}\text { degrees } \\
\text { of } \\
\text { freedom }\end{array}$ & total square \\
\hline Gender & $0 / 236$ & $1 / 458$ & $212 / 644$ & 1 & $212 / 644$ \\
\hline Age & $0 / 552$ & $0 / 712$ & $103 / 807$ & 2 & $207 / 614$ \\
\hline Education & $0 / 591$ & $0 / 646$ & $94 / 176$ & 3 & $282 / 528$ \\
\hline $\begin{array}{l}\text { Duration of } \\
\text { service }\end{array}$ & $0 / 386$ & $1 / 070$ & $156 / 124$ & 2 & $312 / 248$ \\
\hline
\end{tabular}

\section{Conclusion}

The characteristic feature of human society and culture that distinguish one community from the other communities. The culture of life and all things created by humans will take. Cultural needs of diverse groups and includes important human needs. Distance is required between the existing constitution are satisfactory. Needs an important role in the formulation of planning objectives because no notice of deficiencies, adjust any plan, program or plan is futile. No doubt the military did not have any, nor can all the needs of the individual and the 
community to meet the following broad categories. So it is necessary to prioritize needs. Need to be brought. The motivation needs are factors that are important to individuals and organizations. Sensing the needs of the cultural dimension can provide an opportunity for managers and planners with a more comprehensive understanding of environmental, cultural needs and planning to meet the needs on the one hand to reduce absenteeism, burnout, cultural gaps, organizational health and on the other hand, the creation and promotion of cultural development, enhance interpersonal relationships and to provide a dynamic enterprise culture. Unavoidable impacts of the current global requirements to living human beings today is the cultural and human needs are so impressed, and asked if regeneration in humans is manifested. Also, widespread social conflicts in different areas of the community enhance cross-cultural communication, increased attention to the needs of cross-cultural communication gap between generations and in organizations, particularly important to the university. Staffs at the college culture with students and faculty have been lower. This comprehensive review of the research community and is innovative in the field of cultural needs. It is hoped that policy makers and planners to implement the results of this study should be used.

The results showed "camp visit holy shrines of Imam Khomeini", "light path convoys sent to war zones Vance visited the Martyrs", " exhibitions related to each chapter of the Qur'an," "Quran competitions, especially the staff" "family celebrations and religious festivals as" the highest average rank is assigned to. Also, each of the questions, "tournament Reading", "creating and establishing small libraries in each episode," "entrepreneurship courses," "family safari camps held each month," "essay contest for various special occasions "The arrangement is allocated to the highest average ratings. The results of this study indicate the need for sports in each of the questions, "Sport Tournament in every season", "holding various sports", "sports facilities, purchase equipment", "fitness training such as yoga, meditation, and ..." "The academic staff of the club teams in various sports fields" in order to account for the highest average ratings. Henry was also one of the questions in the "art of training courses for the staff", "Celebrating the successful wives (Arts and Education) staff," "authentic Aboriginal arts education in every region of the country", "Understanding economic approaches to art, "" Understanding the cultural and educational centers in Iran The world of "the highest average rank is assigned to. This is entertainment at each of the questions, "Cultural transmission of information via the site," "cultural Twitter for special occasions", "installing electronic signs at the traffic people", "Special Publication cultural issues of the day for employees, "" a cultural roundtables "to the highest average rank is assigned to. Any questions can also "furnish office space, technical and socio-cultural rhetoric," "use of eminent professors and university lectures on the occasion," "Social exhibitions of cultural products (books, CDs, etc.) in each season." "In celebration of

National Family," "increased facilities of cultural products (movies, books, etc.)", "Congratulations to staff holidays and special occasions" arrange their highest average rate to the social dimension data.

\section{Reference}

[1]Fathi Vajargah k .2007. Introduction to employee training programs. Tehran: header [2]Jacobsen, M.J. \& O'Connor, A.(1998). Popu lation needs assessment:A workbook for assessing patients' and practitioners'decision making needs.University of Ottawa.

[3]Fathi Vajargah K. 2006. Service training programs for staff, Tehran: the [4]Gholizadeh A. 2010. Cultural Sociology. Educational pamphlets. Islamic Azad University Branch

[5]Rafi F. M.2010. Anatomy of the community. Tehran: Publication. Page 582 
[6]Rafipor. 2008. The concept of culture in the social sciences. Translate Vhyda F. Tehran: Soroush (Publishing and Broadcasting) Centre

[7]Ismaili R Rubaie K. 2007. Cultural Needs Assessment - Social schoolgirls city. Educational Research Council of Isfahan. 